\title{
FORMAÇÃO, ATUAÇÃO, REGULAMENTAÇÃO E ASSOCIATIVISMO PROFISSIONAL DO ARQUIVISTA BRASILEIRO
}

\author{
FORMATION, PERFORMANCE, REGULATIONS AND PROFESSIONAL \\ ASSOCIATIONS OF BRAZILIAN ARCHIVIST
}

Recebido em: 04/11/2013

Aprovado em: 10/02/2015

\section{Eliseu dos Santos Lima ${ }^{1}$ E Fernanda Kieling Pedrazzi ${ }^{2}$}

\section{RESUMO}

Este artigo tem por objetivo discorrer sobre a trajetória do ensino de Arquivologia, bem como sobre a formação e a atuação do arquivista, no Brasil. É resultado de parte de um trabalho de pesquisa realizado a fim de levantar dados para a monografia "O perfil do profissional arquivista formado pela Universidade Federal de Santa Maria”, apresentada ao Programa de Pós-Graduação Especialização Lato Sensu em Gestão em Arquivos da UFSM. Com base na revisão de literatura, são abordados temas que se relacionam com o perfil e a formação do arquivista, o ensino de Arquivologia, o mercado de trabalho, as Tecnologias da Informação e Comunicação (TIC's) no fazer do arquivista e a regulamentação e o associativismo profissional. Através da análise teórica, conclui-se que aspectos relacionados à formação e capacitação profissional necessitam ser revistos, já que a formação deve preparar o arquivista para atuar como um gestor da informação, o qual precisa investir na formação continuada e no aperfeiçoamento como forma de melhorar suas habilidades. Apesar de ainda ser insuficiente a quantidade de profissionais inseridos no mercado, constata-se que novas opções de atuação para o arquivista têm surgido e que os arquivistas devem estar atentos às TIC's, pois vários indicadores apontam a obrigatoriedade de sua utilização, principalmente no gerenciamento e na preservação de documentos digitais, bem como no desenvolvimento de Sistemas Informatizados de Gestão Arquivística de Documentos.

Palavras-chave: Ensino de Arquivologia; Formação do arquivista; Mercado de trabalho; Regulamentação profissional; Associativismo profissional.

\begin{abstract}
This article aims to discuss the Archivology teaching career and the training and the work of the archivist in Brazil. It is the result of part of the research work conducted to collect data for the monograph "The archivist professional profile from the Federal University of Santa Maria", presented to the Post-Graduate Programme in Management Specialization Lato Sensu Files UFSM. Based on the literature review raised are themes that permeate the archivist's Profile, Archival teaching the, the formation of the archivist, the labor market, the information and communication technologies make Archivist, regulations and professional associations. Through theoretical analysis it was concluded that aspects related to education and professional training need to be reviewed, training should prepare the archivist to act as an information manager, and this professional should invest in continued development and improvement in order to improve their skills. Although still insufficient amount of health professionals involved in the market, it appears that new options of action for the archivist have arisen that archivists should be aware of the information and communication technologies, because everything is moving towards the mandatory use mainly in the management and preservation of digital documents, as well as the development of Computerized Systems Archival document Management.
\end{abstract}

Keywords: Teaching Archival; Training Archivist; Labor Market; Professional regulation; Professional associations. 


\section{Introdução}

A profissão de arquivista, o qual apenas trabalhava em arquivos para garantir a integridade física dos documentos, tem passado por diversas transformações ao longo do tempo. Hoje o arquivista é reconhecido por gerir a informação e não somente o suporte que a sustenta, pois a demanda por informação tratada e por um modo de torná-la acessível é o grande desafio nesta época marcada pela tecnologia.

Nesse contexto, no qual o fazer profissional do arquivista está em constante evolução, o desenvolvimento de pesquisas que busquem analisar como está sua formação e atuação contribui para que se reconheçam os desafios e a inserção desse profissional no mercado de trabalho. Tendo isso em vista, surgiu este estudo, que é resultado do referencial teórico elaborado para a monografia intitulada "O perfil do profissional arquivista formado pela Universidade Federal de Santa Maria", apresentada ao Curso de Pós-Graduação a Distância Especialização Lato Sensu Gestão em Arquivos da Universidade Federal de Santa Maria (UFSM)/Universidade Aberta do Brasil (UAB).

Nesse sentido, esta investigação utiliza a revisão de literatura para fazer um retrospecto da trajetória profissional do arquivista brasileiro quanto à formação, aos desafios enfrentados no mercado de trabalho e ao advento das Tecnologias da Informação e Comunicação (TIC's), bem como aos aspectos relacionados ao associativismo e à regulamentação profissional.

Como a pesquisa pretendia abordar a formação e atuação profissional dos arquivistas, buscou-se levantar referencial teórico que abordasse esses temas. Assim, foi possível formular este artigo com base na literatura arquivística publicada no Brasil, em artigos publicados em periódicos arquivísticos e em anais de eventos da área e em monografias que já haviam tratado sobre a temática apresentada.

\section{Formação e atuação profissional do arquivista brasileiro}

\subsection{Ensino de Arquivologia}

Vedoin (2010, p. 22) afirma que, ao longo dos anos, "o volume informacional tomou proporções gigantescas, o que demandou uma necessidade de formação de profissionais capacitados para gerir as informações arquivísticas que se originavam e se acumulavam". A autora destaca, ainda, que, nesse contexto, começaram-se a fomentar iniciativas que sinalizaram para o estabelecimento do ensino de Arquivologia.

Krause et al. (2005, p. 2), ao se referirem ao desenvolvimento da arquivística, afirmam que:

\begin{abstract}
A partir da segunda metade do século XX, um novo impulso foi dado à arquivologia, com a criação do Conselho Internacional de Arquivos (CIA) pela UNESCO em 1950; a realização dos congressos internacionais de arquivos e das conferências internacionais da mesa-redonda-dos arquivos; o surgimento da associação dos arquivistas; a preocupação com os arquivos privados; a conservação do patrimônio históricodocumental; o surgimento da microfilmagem e da informática aplicada aos arquivos; o crescente interesse pelos arquivos impressos, cartográficos, sonoros e iconográficos; a publicação do Dicionário Internacional de Terminologia Arquivística em 1984 e de outros dicionários nacionais.
\end{abstract}

Richter, Garcia e Penna (2004, p. 74), ao tratarem sobre a evolução do ensino de Arquivologia, afirmam que "o seu berço foi a Europa, onde estão concentradas as escolas mais antigas e a maioria delas". No Brasil, o desenvolvimento da Arquivologia ocorreu principalmente a partir da década de 1970; antes disso, "a formação profissional dos arquivistas vinha sendo feita através de cursos especiais, ministrados pelo Arquivo Nacional, pela Fundação Getúlio Vargas e por outras instituições" (PAES, 2004, p. 43). 
Ao discorrer sobre o nascimento da Arquivologia no Brasil, Richter, Garcia e Penna (2004) explicam que, nos anos de 1970, com a criação da Associação dos Arquivistas Brasileiros (AAB) (1971), presencia-se no cenário nacional o início do desenvolvimento da Arquivologia, seguido da promoção de Congressos Brasileiros de Arquivologia, da criação de cursos de graduação em Arquivologia por universidades e da regulamentação profissional (BRASIL, Lei n. ${ }^{\circ}$ 6.546/1978).

Paes (2004, p. 43) relata que a criação do Curso Superior de Arquivos foi aprovada em 6 de março de 1972 pelo Conselho Federal de Educação, "que a 7 do mesmo mês aprovou o Currículo do Curso de Arquivística como habilitação profissional no ensino de segundo grau". Ainda segundo Paes (2004), em agosto de 1974, foi instituído o Curso Superior de Arquivologia, com duração de três anos.

Posteriormente, por meio da Resolução n. ${ }^{\circ} 28$ de 13 de maio de 1974 , como explica Richter (2004, p. 79), "o Conselho Federal de Educação (CFE) fixou o currículo mínimo dos cursos de graduação em Arquivologia bem como sua duração". Richter, Garcia e Penna (2004) relatam que em 1977 a Universidade do Rio de Janeiro (UNIRIO) outorgou mandato universitário ao Arquivo Nacional para o Curso Permanente de Arquivo, curso esse que foi absorvido pela UNIRIO como Curso Superior de Arquivologia. No mesmo ano, foi criado o Curso de Arquivologia pela Universidade Federal de Santa Maria (UFSM) e, um ano depois, pela Universidade Federal Fluminense (UFF).

Hoje, existem no Brasil 16 cursos de graduação em Arquivologia, "sendo que três deles estão localizados no Rio Grande do Sul: o da UFSM, o da Universidade Federal de Rio Grande (FURG) e o da Universidade Federal do Rio Grande do Sul (UFRGS), sendo os três, como o nome indica, escolas federais" (PEDRAZZI, 2011, p. 3). Além dos cursos localizados no Rio Grande do Sul, a página do Conselho Nacional de Arquivos (CONARQ) na internet aponta a existência dos outros 13 cursos de Arquivologia nas seguintes universidades: Universidade Federal Fluminense (UFF), Universidade Federal do Estado do Rio de Janeiro (UNIRIO), Universidade de Brasília (UNB), Universidade Federal da Bahia (UFBA), Universidade Estadual de Londrina (UEL), Universidade Federal do Espírito Santo (UFES), Universidade Estadual Paulista (UNESP/MARÍLIA), Universidade Estadual da Paraíba (UEPB), Universidade Federal de Minas Gerais (UFMG), Universidade Federal da Paraíba (UFPB), Universidade Federal de Santa Catarina (UFSC), Universidade Federal do Amazonas (UFAM) e Universidade Federal do Pará (UFPA).

Oliveira (2010, p. 2), ao tratar do ensino arquivístico, explica que o curso de Arquivologia tem compromisso com a:

[...] formação de profissionais responsáveis pelo gerenciamento de documentos e das informações arquivísticas, o que significa ser capaz de gerir o acervo documental, de identificar a relevância das informações existentes em diversos suportes, classificar e buscar métodos e tecnologias para disponibilizar essas informações. Além disso, precisam compreender os fluxos informacionais das organizações em que atuam, visando fornecer e/ou armazenar informações que alimentem os processos decisórios e a garantia dos direitos e deveres das organizações, de seus parceiros e funcionários.

Dessa forma, há a expectativa de que o ensino de Arquivologia oferecido pelas universidades forme um profissional capaz de gerir toda a cadeia informacional da organização, independentemente do suporte, e de que os arquivistas possam dirimir o "distanciamento entre as teorias arquivísticas estudadas nos cursos de graduação e a realidade encontrada no mercado de trabalho" (RODRIGUES, 2009, p. 25). 
2.2 Formação do arquivista

Duarte (2006a, p. 148) aponta que:

no princípio, um arquivo organizado certamente satisfazia às necessidades emergenciais de seus produtores e custódios. A revolução promovida pelo advento da tecnologia da informação desconstruiu essa visão de custódia e, atualmente, o arquivista precisa receber formação que o torne receptivo ao comportamento da sociedade do conhecimento e da informação.

Jardim, em entrevista concedida à Cardoso (2006, p. 14), ao falar da inserção do arquivista no mercado de trabalho, explica que:

O desafio é procurar construir essa perspectiva com o futuro arquivista, deixando-o muito alerta para o fato de que, em diversas situações, a alternativa que ele vai ter em termos de início de percurso profissional, é aquela na qual o mercado solicita menos um arquivista e mais um guardador de papel. Com seu arsenal de conhecimento arquivístico, mas também de administração, de relações públicas, de pedagogia, o arquivista poderá alterar os papéis que muitas vezes o mercado está lhe impondo. Identificar esse universo sem transformação constante e atuar nele com qualidade é uma tarefa cada vez mais complexa para o arquivista. Uma formação adequada é absolutamente fundamental para que o futuro arquivista cumpra essa tarefa com desenvoltura.

Souza (2011, p. 87) entende que "diferindo da tradição européia, de caráter histórico, e da norte-americana, com uma vertente para a gestão de documentos, no Brasil, a formação se caracteriza por preparar um profissional dotado de conhecimentos teóricos e habilidades para atuar nas três fases do arquivo". Para Santos (2009, p. 188), "a formação do profissional dos arquivos deve priorizar o desenvolvimento da capacidade de questionar, mudar, procurar, descobrir, inventar, modificar, melhorar, sentir, participar, arriscar e inovar". O autor salienta, ainda, que a formação profissional deve estar ligada aos seguintes aspectos: agir, pensar, refletir, inovar e, sobretudo, recriar. Sousa (2008, p. 14) complementa a ideia de Santos, afirmando que "o sucesso desse processo está na possibilidade de articulação entre teoria e prática, conhecimento e realidade e ensino e pesquisa".

Ao relacionar a universidade com a formação profissional, Oliveira (2010, p. 9) afirma que essa instituição "não pode ignorar as expectativas sociais. Assim como a arquivística, a universidade também carece de remodelagem. Ela precisa se adaptar às demandas contemporâneas, em um momento em que as formações necessitam de uma abordagem mais ampla e menos tecnicista".

Pena $(2005$, p. 5) é enfático ao afirmar que "a formação universitária dos arquivistas pode buscar um profissional dinâmico e competitivo que realmente acolha as vontades da sociedade, e não puramente os anseios do mercado de trabalho". Complementa tal afirmação, explicando que a maioria dos cursos ainda privilegia a formação técnica em detrimento da formação humanista.

Souza (2011, p. 79) afirma que a formação em arquivística deve possibilitar que "o profissional obtenha habilidades e competências para gerenciar os documentos e informações arquivísticas em todas as instâncias e para qualquer pessoa". Já para Oliveira (2010, p. 10), além da necessidade de remodelagem da formação acadêmica, "é preciso destacar a importância do investimento, por parte dos profissionais, na educação continuada, especialmente, para a melhoria no desempenho das atividades multidisciplinares, administrativas e gerenciais".

Jardim, ao ser entrevistado por Cardoso (2006, p. 13), afirma que "é preciso formar um arquivista que seja um cidadão crítico. Crítico em relação à sua profissão, ao seu tempo, à sua inser- 
ção social”. A esse respeito, Pena (2005, p. 7) enfatiza que a formação do arquivista "é, ainda, muito pautada em uma dimensão profissionalizante, que valoriza a prática, ao invés de uma formação mais interdisciplinar e teórica".

Ao tratar dos aspectos que envolvem a formação do arquivista, Richter, Garcia e Penna (2004, p. 77) dizem que esta "deve basear-se em conteúdos que preparem um profissional da área da informação arquivística, com perfil de natureza interdisciplinar".

Stahl (2009) relata que o mercado de trabalho exige do arquivista uma formação que o possibilite atuar frente aos problemas contemporâneos, pois, com o avanço das tecnologias e a crescente demanda documental produzida e recebida pelas instituições públicas e privadas, aumenta cada vez mais a necessidade de profissionais que tratem, gerenciem e preservem as informações e os documentos.

Vedoin (2010, p. 29), quanto ao ensino e à formação do arquivista, acredita que:

melhorias contínuas devem ser agregadas ao ensino de arquivologia no país, para que o profissional formado possa cumprir seu efetivo papel, e, por conseguinte, ser o agente responsável pela implementação de sistemas de gestão da informação arquivística nas organizações. Mas, isso pressupõe uma formação com qualidade e adequada ao mercado, no qual o arquivista transcenda as atividades técnicas e científicas; explore e difunda conhecimentos por meio de uma crítica à realidade que o circunda, e ainda, que tenha como elementos norteadores os padrões éticos e morais do ser humano.

Souza (2011) aponta como fator preocupante a quase inexistência de atividades de pesquisa científica durante a formação dos arquivistas no Brasil, pois "alguns cursos não implantaram a exigência de elaboração da monografia de final de curso, o que afeta e compromete a produção e a difusão de novos conhecimentos" (SOUZA, 2011, p. 97). Sobre isso, Santos (2009, p. 188) afirma que a formação propiciada ao arquivista deve prepara-lo para "desenvolver pesquisas científicas, planejar e coordenar atividades relacionadas à produção, à gestão, à preservação e ao acesso às informações orgânicas; [...] produzir conhecimento, planejar e propor alternativas adequadas à realidade na qual atua".

\section{$2.3 \mathrm{O}$ profissional arquivista}

Segundo Souza (2011), o surgimento do arquivista relaciona-se com a criação dos arquivos ou com o:

[...] momento em que o homem começou a produzir e a custodiar seus documentos. Desde que se iniciou o registro da informação em algum tipo de suporte, a prática de arquivá-la se constituiu como uma atividade que perdura até os dias de hoje. A gestão desses registros está a cargo dos profissionais da informação, os arquivistas (SOUZA, 2011, p. 51).

Os arquivos existem desde a mais remota antiguidade, quando as sociedades passaram a registrar seus conhecimentos em formas rudimentares. Muitas mudanças ocorreram nos registros e mesmo nas formas de arquivamento ao longo dos anos. As mudanças necessárias atualmente são barreiras de uma enorme dimensão e precisam ser vencidas rapidamente, pois o espaço para o profissional de arquivo está aberto e deve ser ocupado.

Bittencourt (2007, p. 1) indica que "o desenvolvimento das organizações e das tecnologias utilizadas tem resultado no crescimento da produção de documentos arquivísticos em suportes diversos e, consequentemente, aumentado a busca por profissionais da área de arquivo". Para Paes (2004, p. 42), "o arquivo possui, atualmente, importância capital em todos os ramos da atividade humana. No entanto, ainda é bastante 
comum a falta de conhecimentos técnicos por parte das pessoas encarregadas dos serviços de arquivamento, falta essa que irá influir, naturalmente, na vida da organização".

Roncaglio (2004, p. 12) infere que manter os arquivos organizados corretamente significa, "em última análise, manter a informação organizada e à disposição para os fins que se fizerem importantes e necessários para as empresas, sejam elas públicas ou privadas, e para a sociedade em geral". Paes (2004, p. 42) também se posiciona sobre esse assunto ao informar que "um serviço de arquivo bem organizado possui valor inestimável. É a memória viva da instituição, fonte e base de informações; oferece provas das atividades institucionais; aproveita experiências anteriores, o que evita a repetição, simplifica e racionaliza o trabalho". Para que esses objetivos sejam atingidos, a autora afirma, ainda, que se torna necessária a preparação de pessoal especializado nas técnicas de arquivo.

Santos $(2009$, p. 183) afirma que "o tratamento da documentação arquivística - gerada e recebida pela instituição em decorrência da realização de suas atividades, ou seja, o arquivo ou fundo institucional - é uma atribuição do arquivista". Este é definido por Bahia e Seitz (2009, p. 471) como o:

profissional liberal que trata a informação e a torna acessível ao usuário final, independente do suporte informacional. Ele trabalha em arquivos públicos e empresariais; hospitalares; fonográfico etc., e pode gerir redes e sistemas de informação, além de recursos informacionais e trabalhar com tecnologia de ponta.

Bahia e Seitz (2009, p. 479) complementam essa ideia, afirmando que "o arquivista precisa estar atento às rápidas mudanças por que passa a sociedade, e desenvolver competências profissionais que lhe permitam oferecer serviços confiáveis e de qualidade aos usuários da informação".
Para Richter (2004), ser arquivista significa compreender a história dos arquivos, a legislação, a terminologia, a teoria e a metodologia arquivística, bem como o contexto da produção de informações e documentos arquivísticos e os procedimentos técnicos relacionados ao tratamento dos arquivos.

Rodrigues, Marques e Costa $(2005$, p. 2) acreditam que "[...] a base fundamental sobre a qual está assentada a Arquivologia e o papel de seu profissional continua a mesma, ou seja, tratar e disponibilizar a informação orgânica registrada para os seus usuários e manter sua integridade e segurança". O pensamento de Krause et al. (2005, p. 3) vai ao encontro dessa afirmação quando explicitam que, "nos dias atuais, os profissionais da informação arquivística continuam sendo chamados para tratar dos problemas decorrentes da produção e do acúmulo de documentos textuais em suporte de papel". Entretanto, são lembrados cada vez com maior frequência para definir:

- organização de acervos sonoros e de imagens;

- tratamento dos acervos registrados em suportes eletrônicos;

- acesso às informações mantidas em redes locais;

- sistemas de informação automatizados;

- padrões de trabalho para a pesquisa científica;

- avaliação de softwares e hardwares;

- desenho de campos de bases de dados a fim de aumentar a qualidade da recuperação de informação.

Nesse cenário, o profissional arquivista "deverá estar habilitado a exercer as diversas atividades a que se propõe, considerando as tecnologias disponíveis. Entre essas atividades, destacam-se: a produção documental/informacional, a 
utilização e destinação de documentos, a gestão da informação, a preservação e a disseminação da informação arquivística" (ANDRADE, 2006, p. 153).

Bellotto (2004) afirma que a função do profissional de arquivo vai além da organização de papéis.

É preciso que o administrador e o burocrata compreendam que o arquivista não é um simples trabalhador administrativo, dentro de um órgão público ou de uma organização privada, que não está ali apenas para passar papéis ou mídia eletrônica às mãos dos interessados. Ele é um provedor da informação administrativa e jurídica. É preciso também que os historiadores compreendam que o arquivista está suficientemente capacitado para elaborar os instrumentos de pesquisa que dão acesso à informação, que sua formação lhe dá elementos que o habilitam a não permitir que se perca a essência da informação na montagem da representação descritiva (BELLOTTO, 2004, p. 306).

Barbosa (2008, p. 18) explica que, "em outros períodos, os arquivistas eram essencialmente técnicos e atuavam nos arquivos para garantir a integridade física e intelectual dos documentos". No que tange a esse assunto, Duarte (2006b, p. 147) afirma que "os profissionais de arquivo não devem depreciar seus papéis como guardiões dos documentos, entretanto, os arquivistas devem transcender seu papel de custódios, se desejam sobreviver como profissionais neste século".

Para Erthal (2005, p. 17), "apesar de a Arquivística ser uma categoria profissional, com princípios e procedimentos bem definidos, são raros os profissionais que se destacam nesse meio e que conseguem transpor as fronteiras limítrofes e, entendidas como únicas, do tecnicismo e da estagnação".

Barbosa (2008, p. 19) afirma que:

diante da complexidade do mundo dos arquivos vale ressaltar que as competências exigidas dos arquivistas vêm se alterando no ambiente arquivístico e as demandas sociais por informação tratada e acessível nesse período póscustodial requerem um profissional apto a lidar com problemas de informação cada vez mais diversos e, ao mesmo tempo específicos.

A ideia defendida por Jardim (2006, p. 16) relaciona-se com a de Erthal e Barbosa, quando afirma que "exercitar o complexo e sofisticado conceito de organicidade, faz toda a diferença entre o que é um arquivista e o que é um guardador de papéis". Bellotto (2004, p. 302) é enfática ao afirmar que "mais do que nunca é preciso que o arquivista trace sua identidade, conheça nitidamente seus contornos e fronteiras, de modo a não confundir com outra a sua profissão".

Ao tratar da especificidade e do alcance do fazer do profissional de arquivo, Bellotto enfatiza que:

o arquivista é o mediador e o possibilitador da concretização do pleno acesso aos documentos. E, não é só, relativamente às informações governamentais ou às informações cidadãs, que o arquivista assume um papel ativo e dinâmico, oposto à atitude passiva que tinha esse profissional nos tempos passados (BELLOTTO, 2007, p. 6).

Ao destacar as atribuições do arquivista, Richter, Garcia e Penna (2004, p. 68) explicam que este "deve estar apto para, além de exercer suas atividades técnico-científicas, produzir e difundir conhecimentos, refletir criticamente sobre a realidade, buscar aprimoramento contínuo e observar os padrões éticos de conduta". Nesse sentido, Bellotto (2004) enumera as seguintes qualidades esperadas do profissional arquivista:

- capacidade de análise e síntese, juntamente com uma aptidão particular para esclarecer situações complexas e ir ao essencial;

- habilidade de formular cla- 
ramente suas ideias, tanto na forma escrita quanto verbal;

- $\quad$ capacidade de julgamento seguro;

- aptidão para tomar decisões sobre questões ligadas à memória da sociedade;

- abertura às novas tecnologias da informação;

- bom senso para tomar resoluções;

- $\quad$ adaptação à realidade e às condições de seu tempo e lugar.

A autora complementa essa lista de expectativas em relação ao arquivista, dizendo que, "ademais de toda essa qualificação de cunho pessoal, deverá ainda estar capacitado profissionalmente para intervir em toda cadeia do tratamento documental, qualquer que seja o suporte" (BELLOTTO, 2004, p. 301). (2005, p. 1):

Para Rodrigues, Marques e Costa

[...] a tendência que parece se configurar para o futuro é a de um profissional que tenha competência para organizar cientificamente e tornar acessível (legal, física e intelectualmente) um conjunto dinâmico de informações, de origens diversas, seja em arquivos, bibliotecas ou centro de documentação, isto é, informações oriundas de diversos serviços de informação. de que:

Duarte (2006b) alerta para o fato

O arquivista, no desempenho de sua função de gestor, deve estar apto a trabalhar as soluções de tratamento funcional da informação e atender às demandas administrativas, jurídicas e técnico-científicas das instituições. Seu perfil profissional supõe acompanhamento da evolução das tecnologias da informação e da produção do conhecimento e domínio de, pelo menos, uma língua estrangeira. Isso faz o seu diferencial, embora, na crescente competitividade, já possa ser considerado uma competência banal (DUARTE, 2006b, p. 149).
Duarte (2006b) complementa essa afirmação, ressaltando que o arquivista "tem sido orientado para satisfazer necessidades informativas, de modo que a administração desenvolva suas funções com rapidez, eficiência e economia, para salvaguardar direitos e deveres das pessoas, contidos nos documentos, e para tornar possíveis a pesquisa e a difusão cultural" (DUARTE, 2006b, p. 1).

Jardim, em entrevista concedida à Cardoso (2006, p. 13), afirma que "um bom arquivista hoje tem que dar conta da complexa especificidade da Arquivologia, mas exercitar seu ofício tendo também conhecimento de outros saberes afins". Além disso, Ramos (2008, p. 25) explica que, "antes de tudo, o arquivista tem de investir em seu talento, qualificando-se e buscando seu aprimoramento contínuo, a fim de que possa acompanhar a evolução dos princípios teóricos e dos processos tecnológicos aplicados em sua área, que, na atualidade, mudam constantemente".

Já para Bellotto (2004, p. 306), “outro não é o papel do arquivista na sociedade contemporânea senão o de colaborar estreitamente para que os fluxos informacionais na sua área de ação possam se dar de forma plena e o mais satisfatória possível, dentro dessa sociedade, toda ela beneficiária de seus arquivos e dos arquivistas".

\subsection{O mercado de trabalho para o arquivista}

Oliveira (2010, p. 2) aponta que “a valorização da informação, como recurso que define a competitividade entre as pessoas, organizações e demais atividades que coexistem no mercado de trabalho, tornou crescente a demanda no mercado por profissionais da informação”. Para Souza (2011, p. 20):

os sinais mais claros do ingresso do arquivista no mercado de trabalho no Brasil são percebidos, inicialmente, nos anos 90 mas com mais intensidade a partir da década seguinte, com 
a publicação de diversos concursos públicos, algo que se tornou mais frequente nestes últimos anos graças à iniciativa dos governos brasileiros.

Por outro lado, Cardoso e Valentim (2007, p. 2) afirmam que "existem nichos tradicionais e emergentes de mercado de trabalho para o arquivista, nos tradicionais temos um campo de trabalho mais consolidado e os emergentes surgem das tendências e necessidades informacionais de determinadas organizações". Os autores enfatizam, ainda, que, com a abertura de novos nichos de mercado para o profissional arquivista, como, por exemplo, os ambientes empresariais, verifica-se um novo paradigma de atuação profissional.

A ideia de Andrade (2009) corrobora essa questão quando afirma que, "embora ainda mais solicitado em órgãos públicos, o arquivista vem ganhando espaço na iniciativa privada". Roncaglio (2004, p. 4), por sua vez, ao tratar desse assunto, afirma que:

O papel do arquivista nas empresas, no entanto, é fundamental. Cabe a este profissional planejar a organização do arquivo, considerando as qualidades inerentes aos documentos de arquivo, a importância da organicidade e do ciclo vital dos documentos. Ele deve distinguir tais documentos de outros conjuntos documentais acumulados por interesses particulares como, por exemplo, os jornais colecionados por um dirigente da empresa. Em seguida, deve-se distinguir as atividades de apoio (materiais, recursos humanos, financeiros, etc.), conhecidas como atividades-meio, das atividades-fim, que são aquelas que justificam a própria existência da empresa e a razão pela qual ela foi criada. Finalmente, um passo importante na organização de arquivos, é identificar no desenvolvimento de cada atividade institucional a série de documentos que se constitui, natural e inevitavelmente. Manter a ordem original dos documentos ou restabelecê-la quando for perdida é outra tarefa do arquivista.
Pedrazzi (2011, p. 4), ao retratar a atuação do arquivista, afirma que "não apenas os conjuntos documentais produzidos e recebidos por órgãos públicos e privados constituem-se arquivos passíveis de receber tratamento do arquivista, como também aqueles referentes à pessoa física". Já para Bahia e Seitz (2009), o mercado de trabalho solicitará ao profissional arquivista diversas competências, inclusive de outras áreas: "espera-se do arquivista, além das competências e habilidades técnicas tradicionais da área, competências empreendedoras para sobreviver ao mercado mutante, globalizado, competitivo que requer profissionais atualizados, éticos e dinâmicos" (BAHIA; SEITZ, 2009, p. 479).

Vedoin (2010, p. 28) acredita que o mercado de trabalho para o arquivista,

assim como na realidade das demais profissões, não é mais o mesmo de anos atrás. A contemporaneidade remete a um profissional atento ao cenário de mudanças, advindas principalmente de inovações em tecnologias e de modernas técnicas e práticas em gestão e administração, exigindo-se assim um profissional em contínua atualização, capacitação e aperfeiçoamento.

Para Duarte (2006b), são múltiplas as possibilidades de atuação do bacharel em Arquivologia no mercado de trabalho, o qual pode atuar em instituições arquivísticas, em setores de documentação ou informação, em centros culturais, em serviços ou redes de informação, em órgãos de gestão do patrimônio cultural ou em órgãos responsáveis pela salvaguarda de acervos documentais. Já Souza (2011, p. 112), em uma definição mais recente sobre o mercado laboral dos profissionais que atuam nos arquivos gerindo as informações, afirma que:

Os espaços de trabalho dos profissionais arquivistas são as empresas públicas e privadas, as instituições arquivísticas públicas e privadas, os centros de documentação e informa- 
ção, as universidades e os centros de pesquisa, as filmotecas e os museus, junto com os bancos de dados e serviços de consultoria arquivística. Além disso, também se inserem as clínicas médicas e os hospitais, as instituições culturais e financeiras, as sociedades e cooperativas, os centros de ensino, os arquivos particulares e as consultorias, além dos órgãos dos poderes legislativo, executivo e judiciário, entre outros. De fato, qualquer instituição produtora de informação é um espaço de trabalho potencial para os arquivistas.

Lopez (2008, p. 6), ao tratar acerca do campo de atuação do arquivista, afirma que este tem:

um vasto campo de trabalho formado por empresas, instituições e organizações das mais diferentes categorias. Neste universo, todas as organizações que mantém algum tipo de registro formal com o estado brasileiro possuem material arquivístico, vital para poderem exercer suas atividades e, muitas vezes, exigido por órgãos fiscalizadores para a comprovação de direitos e para o respeito à legalidade jurídica.

O autor complementa seu raciocínio afirmando que:

[...] todas elas [organizações], para terem existência oficial, realizam atividades típicas de arquivo, ao gerenciar e custodiar, com finalidade de prova, os documentos que informam sobre a própria existência e sobre as atividades realizadas. As organizações que, hoje, buscam o auxílio de um profissional de arquivos (alguns órgãos públicos e algumas grandes empresas) representam apenas uma parcela ínfima da totalidade. Porém, de um modo ou de outro, existem pessoas que se dedicam profissionalmente à gestão de tais documentos na maioria dessas organizações, sem serem reconhecidos formalmente como arquivistas (LOPEZ, 2008, p. 6).
Para Lopez (2008), nas empresas e organizações, podem ser identificados quatro níveis de qualificação para as pessoas que fazem a gestão documental:

- nenhuma qualificação - a gestão é executada intuitivamente pela pessoa que lida cotidianamente com os documentos ou por alguém designado para essa atividade (por exemplo, uma secretária). A gestão limita-se aos aspectos legais mínimos, podendo haver a intervenção de profissionais da contabilidade e/ou do direito. Esse cenário, provavelmente, é hegemônico;

- qualificação mínima - tem um caráter autodidata, de modo que a pessoa designada para a gestão dos documentos busca aprimorar seus conhecimentos arquivísticos por meio de consulta a livros, sítios da internet etc.;

- profissional semicapacitado - há a busca de aprimoramento funcional, com o investimento na participação do pessoal designado para a gestão documental em eventos de formação paralela - tais como minicursos, workshops palestras etc. -, a fim de melhorar sua capacitação e formação. Ainda pode haver a contratação de profissionais que atendam parcialmente aos requisitos da área, porém sem embasamento teórico arquivístico, como, por exemplo: bibliotecários e empresas de gestão eletrônica de documentos, de memória institucional e de gestão da informação. Nas organizações que buscam a qualificação para a gestão documental, esse é provavelmente o cenário mais recorrente;

- profissional capacitado - há uma pessoa (ou um setor em organizações maiores) com formação qualificada que pode ter sido obtida por meio de curso de especialização e de eventos de formação paralela e/ou graduação em Arquivologia. Nos órgãos públicos localizados em regiões nas quais há grande ocorrência do graduado em Arquivologia - como Rio de Janeiro, Porto Alegre e Brasília, por exemplo -, os cargos são preenchidos por profissionais portadores de diploma específico. Nos locais onde a oferta não é abundante, a gestão arquivística nos 
órgãos públicos continua a ser feita por profissionais sem diploma de Arquivologia, contratados formalmente para outras funções.

Andrade (2009), ao tratar da importância dos arquivos nas organizações, diz que "nenhuma empresa existe sem arquivo; mesmo que não saiba disso". A mesma ideia é defendida por Lopez (2008, p. 5) quando afirma que "os arquivos, por se configurarem como um produto natural de atividades administrativas estão presentes em todas as esferas da sociedade e, de um modo ou de outro, existem pessoas executando a atividade de gestão documental arquivística". No entanto, como apontado por Oliveira (2010, p. 2), "os graduados em Arquivologia constatam a predominância da atuação de profissionais de outras áreas, em especial de Administração e de Informática nos cargos de gerenciamento de informações".

Entretanto, Oliveira (2010, p. 5) é enfática ao afirmar que "tanto as atividades gerenciais como as atividades técnico-operacionais são demandadas aos arquivistas". Além disso, como afirma Duarte (2006b, p. 5), "ainda não se reconhece, como deveria, a imprescindível presença desse profissional no desenvolvimento administrativo, sociopolítico e econômico das instituições e, sobretudo, da máquina administrativa do Estado". Lopez (2008, p. 5) aponta que "é baixíssima a quantidade de graduados colocados no mercado, em relação ao tamanho do país e em relação às demandas do mercado por esse tipo de profissional". O autor complementa essa ideia dizendo que, "com a extrema burocratização da vida pública e privada, cada vez mais as atividades rotineiras demandam provas de sua consecução, produzindo os mais diferentes documentos, contínua e progressivamente, o que faz com que a demanda por profissionais qualificados cresça a cada dia". Jardim (2006) afirma que há muitos espaços a serem ocupados pelo pro- fissional arquivista no mercado de trabalho e que a maior inserção do arquivista e a sua maior visualização no mercado de trabalho consistem em um processo que tende a se desenvolver. A esse respeito, Souza (2010, p. 24) aponta novos desafios e novas direções profissionais para os arquivistas, “já que a práxis arquivística tem extrapolado os limites da Lei $n^{\circ}$ 6.546, de 1978, que regulamenta a profissão. Desta maneira, o arquivista vem criando novos espaços de trabalho conforme verificado pela ampliação das ofertas apresentadas no mercado". A autora afirma, ainda, que "as atividades do arquivista são essenciais para toda organização e no mundo laboral esperase que o profissional obtenha o mesmo reconhecimento, ou seja, um profissional indispensável"' (SOUZA, 2010, p. 24).

Stahl (2009), por sua vez, explicita que há um mercado de trabalho amplo para o arquivista, o qual continua em expansão devido ao fato de que, cada vez mais, as empresas produzem documentos, que testemunham sua criação, sua evolução e seu desenvolvimento e que precisam de profissionais arquivistas para organizá-los a fim de facilitar a busca pelas informações.

Souza (2011, p. 22) acredita que ultimamente "têm-se ampliado as oportunidades no mercado de trabalho para este profissional, e o reconhecimento de suas atribuições começa a mostrar um avanço significativo, principalmente na última década". Apesar disso, a autora lembra que a ausência de estudos sobre o mercado de trabalho faz com que a universidade desconheça onde estão atuando os graduados e que "o mercado laboral obterá crescimento na medida em que se criarem novos cursos nos quais se requeiram a prática de uma maior sintonia entre os espaços de formação, os coletivos profissionais e os arquivistas" (SOUZA, 2011, p. 228). 
2.5 As Tecnologias da Informação e Comunicação (TIC's) no fazer do arquivista

Ramos (2008) acredita que as profissões nunca sofreram mudanças tão drásticas quanto as provocadas pelas Tecnologias da Informação e da Comunicação (TIC's). A autora pondera que "algumas profissões, no entanto, sofreram muito mais este impacto, tais como os arquivistas e bibliotecários, cujo fazer esteve sempre ligado ao processamento da informação e à difusão do conhecimento" (RAMOS, 2008, p. 24).

Atualmente, o arquivista, além de ter o domínio das funções e atividades que regem a sua profissão, deve estar atento às novas tecnologias voltadas aos arquivos, pois, como aponta Bellotto (2004, p. 299), "o arquivista hoje não pode esquecer que vive e atua profissionalmente na chamada era da informação, na qual as Tecnologias da Informação e Comunicação têm presença marcante". O pensamento de Souza (2011, p. 76) relaciona-se ao de Bellotto, quando afirma que, "se anteriormente o perfil exigido era eminentemente técnico, inclusive com a primazia de uma função de guardador da informação, atualmente os arquivistas [...] devem ter um perfil com competência para as tecnologias da informação e atuar, fundamentalmente, como disseminadores das informações".

Erthal (2005, p. 14), ao manifestar-se sobre as TIC's e a Arquivologia, diz que "as novas tecnologias têm brindado a possibilidade de automatizar muitos processos com inúmeras vantagens: a gestão administrativa, o armazenamento e substituição de suportes, as transferências, o controle sobre o descarte, a descrição, a difusão". A autora enfatiza, ainda, que esse novo mundo de possibilidades exige do profissional arquivista a aproximação com essa nova e presente realidade da informática.

Para Bellotto (2004), o crescimento do uso das tecnologias é responsável pelas mudanças nas necessidades infor- macionais da sociedade, e "o arquivista só poderá cumprir a contento suas tarefas se compreender esse quadro atual de sua profissão, profundamente marcado pela informática" (BELLOTTO, 2004, p. 305). Já Krause et al. (2005, p. 3), ao mencionarem a rápida transformação tecnológica, afirmam que:

Mesmo com todas as permanentes e cada vez mais aceleradas inovações, o computador não substitui o homem na tomada de decisões. Cabe ao arquivista desenvolver-se constantemente para cumprir o papel de promover da forma mais otimizada e precisa possível as ações estratégicas de gerenciamento de informação e definições de planos de ação por parte das organizações.

Para Erthal (2005, p. 13), "o impacto das novas tecnologias da informação sobre as práticas arquivísticas não podem ser ignoradas e deixar de ser discutidas, uma vez que é preciso entender que elas chegaram para ocupar um lugar permanente no desenvolvimento dos trabalhos arquivísticos". Ao tratar da inserção de novas tecnologias no trabalho do arquivista, Krause et al. (2005, p. 5) afirmam que:

As novas tecnologias transformaram as formas tradicionais de gerenciamento da informação colocando o arquivista diante de um novo contexto onde a tecnologia é a principal ferramenta para o arquivamento, preservação e distribuição da informação. $\mathrm{O}$ arquivista tem à sua frente o desafio de conhecer e adaptar-se aos novos suportes e formas de gestão da informação criados pela evolução tecnológica. Novas habilidades foram inseridas ao currículo do arquivista colocando-o como um profissional que deve reconhecer a informática como ponte para seu sucesso, como gestor e mediador da informação.

Os mesmos autores complementam seu enunciado dizendo que "o ar- 
quivista, enquanto cientista da informação tem um papel de suma importância a desempenhar no âmbito da construção e gerenciamento de sistemas de informações" (KRAUSE et al., 2005, p. 6), pois é do arquivista a responsabilidade de mediar a informações, cabendo a ele identificar necessidades, particularidades, objetivos e aplicações que sejam viáveis aos usuários.

A ideia de Bellotto (2004, p. 305) assemelha-se a dos autores supracitados quando diz que "deve haver a colaboração dos arquivistas nos processos de elaboração de software, para que não se percam os vínculos da informação arquivística com os princípios da proveniência e da organicidade, levando-se em conta, ainda, a padronização internacional de procedimentos". Ainda em sua exposição, a autora explica que "os especialistas chamam a atenção dos arquivistas para o fato de que todo o processamento que se dê a informação arquivística não pode se afastar dos princípios teóricos básicos da arquivística" (BELLOTTO, 2004, p. 300).

Stahl (2009) afirma que, com a mudança do contexto social e tecnológico, muda também o contexto de atuação do arquivista, "o qual pode dispor de ferramentas das tecnologias da informação para auxiliar o trabalho arquivístico, porém, não extingue ou substitui a necessidade do profissional arquivista que está capacitado para desempenhar as atividades relacionadas à gestão documental/informacional".

Krause et al. (2005, p. 4), por sua vez, afirmam que, "em países como o Brasil, no qual as tecnologias não estão disponíveis em todos os setores sociais e institucionais, o papel é ainda o melhor e o mais utilizado suporte de informação". Os autores salientam que é muito importante o profissional da informação dominar as técnicas arquivísticas e saber aplicá-las em conjunto com as novas tecnologias, agregando valor ao fazer tecnológico.

Nesse contexto, Barreto (2006, p.
1) acredita que "a mudança de mídia a ser preservada, sejam arquivos em papel ou arquivos digitais, necessitam do trabalho do profissional de arquivo". Já para Jardim (2006, p. 19), “o imperativo tecnológico resultante dos avanços das Tecnologias da Informação e Comunicação tem influenciado diretamente os modos de produção, armazenagem e uso social da informação arquivística". Conforme o autor, outra influência da Arquivologia no meio tecnológico consiste no gerenciamento arquivístico e na preservação de documentos eletrônicos. Dessa forma, como apontado por Andrade (2006, p. 158), "espera-se do arquivista competência suficiente para exercer as atividades que a ocupação demanda, o que exige habilidades para lidar com as novas Tecnologias de Informação e Comunicação. Elas já fazem parte dos seus instrumentos de trabalho e serão cada vez mais comuns, caminhando celeremente para a obrigatoriedade de uso". A esse respeito, Souza (2011) explicita que os avanços tecnológicos refletem-se nas tarefas e nos serviços dos arquivos e que os arquivistas devem manter uma atualização contínua a fim de serem profissionais reconhecidos e respeitados na sociedade.

\subsection{Regulamentação profissional}

Pedrazzi (2011, p. 3) relata que, "com a criação de cursos superiores de graduação, a partir de 1977, tornou-se imperativa a regulamentação da profissão de arquivista". Em julho de 1978, foi publicada a Lei n. ${ }^{\circ}$ 6.546, que dispõe sobre a regulamentação das profissões de Arquivista e de Técnico de Arquivo e dá outras providências.

O exercício da profissão de arquivista só é permitido, segundo a Lei n. $^{\circ}$ 6.546 , de 04 de julho de 1978 , e o Decreto n. ${ }^{\circ} 82.590$, de 06 de novembro de 1978 (que regulamentam a profissão), aos diplomados por Curso Superior em Arquivologia ou àqueles que, na época de publicação da Lei, comprovaram pelo 
menos cinco anos ininterruptos de atividade ou dez intercalados, sendo estes provisionados com o registro de arquivista. Souza (2011, p. 51) explica que "somente nestes dois casos reconhecese a dita lei ao profissional arquivista no Brasil, de maneira que a legislação cria um obstáculo ao impedir o exercício ao profissional sem formação".

Ainda de acordo com essa Lei, para exercerem a profissão, esses profissionais devem estar registrados em uma Delegacia Regional do Trabalho (DRT) do Ministério do Trabalho. Dessa forma, em nosso país, "habilitam-se para exercer a profissão de arquivista nos arquivos, profissionais que cursaram a graduação em Arquivologia, ao amparo legal da Lei $n^{\circ}$. 6.546, de 4 de julho de 1978" (SOUZA, 2011, p. 20).

$\mathrm{O}$ artigo $2^{\mathrm{o}}$ da Lei . $^{\circ}$ 6.546, de 04 de julho de 1978 , que regulamenta a profissão, atribui ao arquivista as funções de:

planejamento, organização e direção de serviços de arquivo; planejamento, orientação e acompanhamento do processo documental e informativo; planejamento, orientação e direção das atividades de identificação das espécies documentais e participação no planejamento de novos documentos e controle de multicópias; planejamento, organização e direção de serviços ou centro de documentação e informação constituídos de acervos arquivísticos e mistos; planejamento, organização e direção de serviços de microfilmagem aplicada aos arquivos; orientação do planejamento da automação aplicada aos arquivos; orientação quanto à classificação, arranjo e descrição de documentos; orientação da avaliação e seleção de documentos, para fins de preservação; promoção de medidas necessárias à conservação de documentos; elaboração de pareceres e trabalhos de complexidade sobre assuntos arquivísticos; assessoramento aos trabalhos de pesquisa científica ou técnico-administrativa; desenvolvimento de estudos sobre documentos culturalmente importantes.
Para Souza (2011, p. 74), "as atribuições previstas na legislação propõem a aplicação de metodologia para a gerência dos arquivos, ou para a orientação das atividades operacionais, sobretudo o tratamento técnico a ser aplicado aos documentos". A autora, em 2011, data em que publicou sua obra, destaca que "a regulamentação da profissão ocorreu há 33 anos e percebe-se que carece de uma revisão de suas atribuições. A formação acompanha, praticamente, a mesma existência temporal e revela-se com um quantitativo insuficiente para responder às demandas do mercado" (SOUZA, 2011, p. 13).

2.7 Associativismo profissional dos arquivistas

Ao tratar sobre as associações profissionais e definir os seus objetivos, Link (2009, p. 17) afirma que:

As associações são sociedades de cunho científico, criadas com o objetivo de auxiliar os profissionais e estudantes com atividades que agreguem valor aos seus currículos, como cursos, palestras, congressos, jornadas, encontros, simpósios e demais eventos científicos. Elas devem cuidar de reciclar os conhecimentos técnico-científicos, tendo como objetivo atualizá-los diante de uma sociedade que exige cada vez mais qualidade, especialização, excelência e competência.

Já para Souza (2011, p. 134), “os objetivos principais das associações profissionais existentes no Brasil consistem em congregar os profissionais e lutar por seus direitos". Afirma, ainda, que as associações de arquivistas, além de organizar cursos e outros eventos no intuito de melhorar a categoria,

oferecem alguns benefícios que atendem a todos os associados. Por exemplo, convênios com clínicas odontológicas, cursos de idiomas, livrarias, venda de livros de publicação nacional 
e internacional e descontos em instituições que oferecem cursos específicos da área (SOUZA, 2011, p. 134).

Souza (2011) afirma que, no Brasil, a responsabilidade de fiscalização do exercício profissional é dos Conselhos Profissionais e que, "na ausência de um conselho profissional, as associações profissionais desempenham o papel de representantes da categoria, ainda com pouco eco" (p. 13). A autora expõe que,

No que se refere aos arquivistas, até hoje não foi constituído um Conselho que possa exercer a função de órgão fiscalizador do exercício da profissão. Não obstante, foram apresentadas ao Governo Federal três propostas de criação de um conselho próprio (surgidas como iniciativas isoladas das associações profissionais nos anos 1997, 2000 e 2004), mas todas foram arquivadas (SOUZA, 2011, p. 134).

Já Esposel (2008) explica que o projeto de regulamentação da profissão de arquivista previa a criação de um Conselho Federal. Porém, durante o trâmite do projeto de lei, acabou ocorrendo uma modificação que exige dos arquivistas, dos técnicos de arquivo e dos provisionados o registro no Ministério do Trabalho.

Com a ausência de um consetho profissional para arquivistas, como apontado por Souza (2011, p. 134), “as associações não só exercem seu papel de representar a categoria profissional mas, também, colaboram com as instâncias governamentais em prol dos direitos dos arquivistas e de reconhecimento de seu papel na sociedade".

O marco de criação do movimento associativo de arquivistas no Brasil é o surgimento da Associação dos Arquivistas Brasileiros (AAB), em 1971, antes mesmo da criação dos cursos de graduação em Arquivologia e da regulamentação da profissão pela Lei n. ${ }^{\circ}$ 6.546, de 04 de julho de 1978. Situação semelhante ocorreu em Brasília, onde também "surgiu um núcleo da $\mathrm{AAB}$, antes da criação do curso em 1991. Outro exemplo apresenta-se em São Paulo, com a Associação de Arquivistas de São Paulo (ARQ-SP), onde não existe curso de graduação em Arquivologia" (SOUZA, 2011, p. 116).

Ao apontar os grandes feitos da AAB, Souza (2011) destaca a definição de um currículo mínimo para os cursos de graduação e a atuação determinante quanto à regulamentação da profissão.

A AAB funcionou com os núcleos regionais até 1998, quando optou por extingui-los, o que possibilitou o surgimento de novas associações. Dessa forma, como explica Souza (2011, p. 132):

[...] foram criadas novas associações profissionais: Associação Brasiliense de Arquivologia, Abarq, Associação dos Arquivistas de São Paulo, ARQ-SP e Associação dos Arquivistas do Rio Grande do Sul, AARGS. Depois foram criadas as demais Associações. Atualmente existem nove associações profissionais distribuídas por todo o país: São Paulo, Brasília, Distrito Federal, Rio Grande do Sul, Bahia, Espírito Santo, Paraná e a última criada em Goiânia, Goiás. Somente o Rio de Janeiro conta com duas associações profissionais.

A autora lembra, ainda, que, nos estados em que se estabeleceram os últimos cursos de graduação em Arquivologia em funcionamento no Brasil (Paraíba, Amazonas, Minas Gerais, Santa Catarina e Pará), ainda não existem associações profissionais.

Durante a I Conferência Nacional de Arquivos (I CNARQ), ocorrida em Brasília em 2011, a Plenária apoiou a criação do Conselho Federal de Arquivologia. A criação desse Conselho, desde a primeira edição da CNARQ, continua sendo discutida, como no encontro promovido pela Associação dos Arquivistas do Estado do Rio de Janeiro (AAERJ), na Universidade Federal do Estado do Rio de Janeiro (UNIRIO), em outubro de 2014, quando foi debatida a experiência dos Conselhos Federais da Museolo- 
gia e da Biblioteconomia. Esse encontro realizado na UNIRIO pretendeu iniciar uma discussão a ser ampliada em nível nacional com o intuito de tornar viável a criação do Conselho Federal de Arquivologia, para que assim houvesse maior fiscalização profissional e valorização da área arquivística e do profissional arquivista no mercado de trabalho.

Em meio às discussões acerca da criação do Conselho Federal de Arquivologia, em janeiro de 2015, a Diretoria da Associação dos Arquivistas Brasileiros (AAB) tornou público o início do processo de desativação da entidade, tendo em vista o fechamento dos núcleos regionais da $\mathrm{AAB}$, fato que compromete sua representatividade nacionalmente. As dificuldades enfrentadas pelas diretorias anteriores no que diz respeito à gestão da entidade e à diminuição da contribuição dos sócios ao longo dos anos dificultaram a manutenção das atividades da $\mathrm{AAB}$ em nível nacional.

\section{Considerações finais}

Neste estudo sobre a formação e a atuação do arquivista no Brasil, verifica-se que os aspectos relacionados à formação e capacitação profissional necessitam ser revistos, tanto para melhor preparar o profissional de acordo com as necessidades do mercado quanto para que o arquivista esteja sempre atualizado, buscando novas formas de aperfeiçoar sua formação. É mister lembrar que ainda é insuficiente a quantidade de arquivistas no mercado de trabalho e que isso se reflete no reconhecimento desse profissional na sociedade. No entanto, percebem-se novos nichos de atuação para o arquivista, sobretudo com o advento das Tecnologias da Informação e Comunicação (TIC's).

A formação de ensino superior deve preparar o arquivista para atuar como um gestor da informação e não apenas como um profissional voltado ao desenvolvimento de atividades técnicas, função com que muitas vezes os arquivistas se deparam no início de suas tra- jetórias profissionais. Como o arquivista não pode ser um profissional parado no tempo (estático), deve investir na formação continuada e no aperfeiçoamento como forma de melhorar suas habilidades, aprofundar sua formação e acompanhar o surgimento de novas tecnologias e soluções, o que, na área arquivística, ocorre constantemente. Assim, ao investir na formação continuada, o arquivista estará contribuindo com a produção e divulgação de novos conhecimentos advindos da pesquisa científica em benefício da arquivística.

Ao ingressar no mercado de trabalho, o arquivista, muitas vezes, depara-se com profissionais de outras áreas atuando no gerenciamento de informações/documentos. Entende-se que isso talvez esteja relacionado ao fato de ainda ser insuficiente a quantidade de profissionais inseridos no mercado, se levarmos em conta o tamanho do país, o número de formados por ano e a demanda pelo profissional qualificado no mercado de trabalho.

A criação de novos cursos de Arquivologia, de certa forma, supriria a demanda pelo profissional, além de contribuir para o crescimento do mercado laboral para o arquivista. É preciso considerar, ainda, que o mercado de trabalho para o arquivista vem se expandindo também na iniciativa privada, sobretudo em empresas e serviços de consultoria, devido ao reconhecimento da importância do gerenciamento das informações.

$\mathrm{O}$ arquivista não pode esquecer que, além de ter o domínio das funções e atividades que regem sua profissão, deve estar atento às TIC's, pois o atual contexto indica a obrigatoriedade de sua utilização no futuro, inclusive em atividades como controle da produção, tramitação, classificação, destinação, descrição e controle de descarte de documentos. O arquivista deve aproximar-se, assim, da realidade das TIC's, seja no gerenciamento e na preservação de documentos digitais, seja no desenvolvimento de Sistemas Informatizados 
de Gestão Arquivística de Documentos (SIGAD's), auxiliando na construção ou no gerenciamento desses sistemas que, se respeitada a implementação prévia de uma política de gestão arquivística de documentos, trarão relevantes contribuições para o desempenho de suas atividades.

No que concerne à regulamentação profissional, cabe salientar que a Lei que regulamenta a profissão (Lei n. ${ }^{\circ}$ 6.546, de 04 de julho de 1978) necessita ser revisada, pois a atuação profissional do arquivista já extrapolou as atribuições concedidas a esse profissional na legislação.

Com relação ao associativismo profissional, percebe-se que apenas os estados onde foram criados os últimos cursos de graduação em Arquivologia (Paraíba, Amazonas, Minas Gerais, Santa Catarina e Pará) ainda não contam com associações. Apesar disso, espera-se que, à medida que for ocorrendo a inserção desses novos graduados no mercado de trabalho, sejam criadas associações profissionais que atuem na defesa dos arquivistas durante sua vida laboral.

\section{Referências}

1. ANDRADE, R. S. Tecnologia, memória e a formação do profissional arquivista. Rio de Janeiro, v.2, n.1, p. 149-159, jan/jun. 2006. Disponível em: $<$ www.arquivistica.net $>$. Acesso em: 20 jan. 2011.

2._. Iniciativa Privada abre espaço para arquivistas. 2009. Disponível em: <http:// www.g1.globo.com/sites/especiais/ noticias/0,,MUL964339-15526,00-IN ICIATIVA+PRIVADA+ABRE+ESPA CO+PARA+ARQUIVISTAS.html>. Acesso em: 20 jan. 2011.

3. BAHIA, E. M. dos S. SEITZ, E. M. Arquivista empreendedor. Revista ACB: Biblioteconomia em Santa Catarina, Florianópolis, v.14, n.2, 468-
481, jul./dez., 2009. Disponível em: $<$ www.revista.acbsc.org.br>. Acesso em: 20 jan. 2011.

4. BARBOSA, S. L. R. Avaliação de competências informacionais em formandos de Arquivologia da UFBA. 2008. Monografia (Graduação em Arquivologia) - Universidade Federal da Bahia, Salvador, 2008.

5. BARRETO, A. R. O arquivista no atual mundo dos negócios. In: Congresso Nacional de Arquivologia, 2, 2006, Porto Alegre. Anais... Porto Alegre: AARGS, 2006.

6. BITTENCOURT, P. R.; VIEIRA, T. de O. Perspectivas da Graduação em Arquivologia na Modalidade Educacional à Distância no Brasil. In: Congresso de Arquivologia do Mercosul, 7, 2007, Viña Del Mar. Anais... Viña Del Mar: Associação de Arquivistas do Chile, 2007.

7. BELlOTTO, H. L. O arquivista na sociedade contemporânea. Arquivos Permanentes: tratamento documental. $2^{\mathrm{a}}$ ed: Rio de Janeiro: Editora FGV, 2004.

8. dadãs na formação do arquivista. In: Congresso de Arquivologia do Mercosul, 7, 2007, Viña del Mar. Anais... Viña del Mar: Associação de Arquivistas do Chile, 2007.

9. BRASIL. Lei $n^{0}$. 6.546, de 4 de julho de 1978. Dispõe sobre a regulamentação das profissões de Arquivista e de Técnico de Arquivo, e dá outras providências. Disponível em: <http://www.jusbrasil. com.br/legislacao/128373/lei-654678>. Acesso em: 10 jan. 2012.

10. CARDOSO, D. R.; VALENTIM, M. L. P. Perfil do profissional arquivista para atuar com a gestão documental em ambientes empresariais. In: Encontro Nacional de Estudantes de Arquivologia, 11, 2007, Santa Maria. Anais... Santa Maria: UFSM, 2007.

11. DUARTE, Z. Arquivo e arquivista: conceituação e perfil profissional. In: Congresso Nacional de Arquivologia, 2, 2006, Porto Alegre. Anais... Porto 
Alegre: AARGS, 2006a.

12. Quem é este profissional $\mathrm{O}$ arquivista? In: Congresso Nacional de Arquivologia, 2, 2006, Porto Alegre. Anais... Porto Alegre: AARGS, 2006b.

13. ESPOSEL, J. P. 04 de julho - Dia da independência do arquivista. Entrevista concedida à ENARA. 2008. Disponível em: <http:// www.fortium.com.br/blog/detalhar. php?id=27\&idn=17>. Acesso em: 02 mar 2011 .

14. ERTHAL, D. O papel do profissional arquivista na gestão de informações na sociedade do conhecimento. In: Congresso de Arquivologia do Mercosul, 6, 2005, Campos do Jordão. Anais... Campos do Jordão: ARQSP, 2005.

15. JARDIM, J. M.; CARDOSO, J. C. Entrevista com José Maria Jardim. Arquivistica net. Rio de Janeiro, v.2, n.1, p.7-21, jan/jun. 2006. Disponível em: <www.arquivistica.net>. Acesso em: 20 jan. 2011.

16. KRAUSE, C.; PAGANINI, G.; PROVEDEL, A.; CORRÊA, L. H. M. A atuação do arquivista no desenvolvimento e na administração de sistemas de informação computadorizados. In: Congresso de Arquivologia do Mercosul, 6, 2005, Campos do Jordão. Anais... Campos do Jordão: ARQSP, 2005.

17. LINK, J. Z. R. O mercado de trabalho dos arquivistas sócios da Associação dos Arquivistas do RS (AARS). 2009. Monografia (Especialização em Gestão em Arquivos) - Universidade Federal de Santa Maria, 2009. Disponível em: < http://bibweb.si.ufsm.br/>. Acesso em: 30 mar 2011.

18. LOPEZ, A. P. A. O ser e o estar arquivista no Brasil de hoje. In: Congresso Brasileiro de Arquivologia, 15, 2008, Goiânia. Anais... Goiânia: AAG. 2008. Disponível em <www.aag.org.br>. Acesso em: 20 jan. 2011.

19. MALDANER, S. S. Processos educativos \& capital intelectual: um estudo do papel do arquivista nas instituições. 2010. 78 f. Monografia (Especialização Lato-Sensu Gestão em Arquivos) - Universidade Federal de Santa Maria/Universidade Aberta do Brasil), Três de Maio, 2010.

20. OLIVEIRA, F. H. de. As habilidades demandadas aos arquivistas para o exercício profissional no mercado de trabalho de Brasília. In: Congresso Nacional de Arquivologia, 4, 2010, Vitória. Anais... Vitória: AARQES, 2010.

21. PAES, M. L. Arquivo: teoria e prática/ Marilena Leite Paes. - 3. ed. Rev. Ampl. Rio de Janeiro: Editora FGV, 2004.

22. PEDRAZZI, F. K. Difusão da identidade do arquivista: a profissão e as estratégias de comunicação para o público infantil. Disponível em: $<$ WWW.ufsm.br/sipecom/anais/ artigos/culturaidentidade/PEDRAZZI. pdf.> Acesso em: 31 de out 2011.

23. PENA, D. A formação universitária do arquivista brasileiro. In: Congresso de Arquivologia do Mercosul, 6, 2005, Campos do Jordão. Anais... Campos do Jordão: ARQSP, 2005.

24. RAMOS, E. N. O aporte da noção de empreendedorismo na formação do arquivista. 2008. Monografia (Graduação em Arquivologia) - Universidade Federal da Bahia, Salvador, 2008.

25. RICHTER, E. I. S.; GARCIA, O. M. C.; PENNA, E. F. O arquivista. In: Introdução à Arquivologia. Santa Maria: FACOS-UFSM: 2004. $2^{\mathrm{a}}$ Edição, 110 p.

26. RODRIGUES, C. P. As políticas de preservação de documentos digitais na realidade do profissional arquivista atuante nas instituições de ensino superior do RS. 2009. Monografia (Especialização em Gestão em Arquivos) - Universidade Federal de Santa Maria, 2009.

27. RODRIGUES, G. M.; MARQUES, A. A. da C.; COSTA, L. C. Arquivistas e Arquivologia: lugares de formação, competências e exigências profissionais. In: Congresso de Arquivologia do Merco- 
sul, 6, 2005, Campos do Jordão. Anais... Campos do Jordão: ARQSP, 2005.

28. RONCAGLIO, C.; SZVARÇA, D. R.; BOJANOSKI, S. de F. Arquivos, gestão de documentos e informação. Encontros Bibli: revista eletrônica de biblioteconomia e ciência da informação, ano 9. n. esp, p. 1-13, 2004. Disponívelem: $<$ https://periodicos.ufsc. br/index.php/eb/article/viewFile/15182924.2004v9nesp2p1/5486>. Acesso em: 24 fev. 2011.

29. SANTOS, V. B. dos. O arquivista como profissional da informação. In: Arquivística: temas contemporâneos: classificação, preservação digital, gestão do conhecimento. $3^{\mathrm{a}}$ ed: Distrito $\mathrm{Fe}-$ deral: SENAC, 2009.

30. SOUSA, R. T. B. de. Os desafios da formação do arquivista no Brasil. In: Congresso Brasileiro de Arquivologia, 15, 2008, Goiânia. Anais... Goiânia: AAG, 2008. Disponível em: <www. aag.org.br>. Acesso em: 20 jan. 2011.

31. SOUZA, K. I. M. de S. Visibilidade do arquivista no mundo do trabalho. In: Congresso Nacional de Arquivologia, 4, 2010, Vitória. Anais... Vitória: AARQES, 2010.

32. Arquivista, visibilidade profissional: formação, associativismo e mercado de trabalho/Kátia Isabelli Melo de Souza. - Brasília: Starprint, 2011.

33. STAHL, S. J. O mercado de trabalho para arquivistas nas prefeituras do RS. 2008. Monografia (Especialização em Gestão em Arquivos) - Universidade Federal de Santa Maria, 2009.

34. VEDOIN, A. M. R. Tendência empreendedora: Perfil dos Alunos do Curso de Arquivologia da Universidade Federal de Santa Maria. 2010. Monografia (Especialização em Gestão em Arquivos) - Universidade Federal de Santa Maria, Santa Maria, 2010. 